\section{Ullanlinna Narcolepsy Scale}

Helga Peter

Marburg, Deutschland

\section{Englischer Begriff}

Ullanlinna Narkolepsiefragebogen

\section{Definition}

Validierter, einfacher Fragebogen mit elf Fragen zur differentialdiagnostischen Erfassung der Symptome Tagesschläfrigkeit und Kataplexie bei Patienten mit Verdacht auf \ „Narkolepsie“. Der Fragebogen unterscheidet zuverlässig zwischen Patienten mit Narkolepsie, „Obstruktive Schlafapnoe“, ๖,Multiple Sklerose“ und $\triangleright$ „Epilepsie“. 